\title{
Reading conditions in schools: a review of fluorescent lighting, ultra-white paper, unexplained learning difficulties, and visual stress in the classroom
}

\author{
Stephen J. Loew ${ }^{*}$ \\ University of New England
}

\begin{abstract}
Reading involves complex visual and phonological processing, however, the crucial first step in the reading process begins when the retina receives photons reflected off the written page, and this is greatly influenced by three external factors: the amount of illumination; the spectral properties of the illumination; and the reflectance properties of the page being read (i.e. brightness, contrast). These three fundamental factors, which are essential to visual comfort and reading efficacy, have changed significantly in the classroom over the past two decades. Herein, current issues relating to these factors are reviewed and levels of literacy and numeracy in today's school students are compared to long-term trends (with a specific focus on Australia, the author's country of residence). This theoretical paper also examines the author's hypothesis that relatively recent changes to the reading conditions in primary schools have impacted upon a significant subgroup of students with visual sensitivities that can potentially cause reading difficulties. In particular, the latent role that the common visual processing deficit Meares-Irlen Syndrome (MIS), also referred to as Visual Stress (VS), may play in student performance is scrutinised, as is the possibility that increased fluorescent lighting and brighter visual media may be detrimental to learning for students in general.
\end{abstract}

Keywords: Reading difficulties; fluorescent lighting; ultra-white paper; visual stress; Meares-Irlen syndrome.

Condiciones de lectura en las escuelas: luces fluorescentes, papel, dificultades de aprendizaje y estrés visual.

Resumen. La lectura es una habilidad que implica un procesamiento visual y fonológico complejo. Sin embargo, el primer paso crucial en el proceso de lectura comienza cuando la retina recibe reflejados fotones desde la página escrita. Esto está muy influenciado por tres factores externos: la cantidad de la iluminación; las propiedades espectrales específicas de iluminación; y las propiedades de reflectancia de la página que se está leyendo (principalmente, brillo, contraste). Estos tres factores que son esenciales para el confort visual y la eficacia de la lectura, han cambiado significativamente en el aula escolar durante las últimas dos décadas. En este trabajo se revisan los temas actuales relacionados con estos factores y se comparan los niveles de alfabetización y aritmética en los estudiantes de hoy en día con las tendencias de lectura a largo plazo, todo ello con un enfoque específico de Australia. Este artículo teórico también examina la hipótesis de que cambios relativamente recientes a las condiciones de lectura en las escuelas de Primaria han impactado en un subgrupo significativo de estudiantes con sensibilidades visuales que pueden causar dificultades de lectura. En particular, el papel latente que el déficit de procesamiento visual común denominado Meares-Irlen Syndrome (MIS), también conocido como Visual Stress (VS), puede jugar un papel fundamental en el rendimiento de los estudiantes, examinando la posibilidad de que el aumento de la iluminación fluorescente y materiales de lectura más brillantes pueden ser perjudiciales para el aprendizaje de los estudiantes en general.

Palabras clave: Dificultades de lectura; iluminación fluorescente; papel ultra-blanco; estrés visual; síndrome de Meares-Irlen

There is growing agreement among some educational researchers that student literacy and numeracy levels in a number of OECD

Received: 01/05/2017 - Accepted: 15/05/2017 - Avaliable online: 20/06/2017

${ }^{*}$ Correspondence: Stephen J. Loew.

University of New England.

NSW 2351, Armidale, Australia.

E-mail: sloew@une.edu.au countries have been declining during the last 15 years. This increasingly common view has come about following relatively recent reviews of student performances in successive international literacy and numeracy tests, first initiated by the OECD in 2000, and which have since been carried out on a 3-yearly basis under the Programme for International Student 
Assessment (PISA). Interestingly however, reviews that have examined longer-term literacy and numeracy test-score data (over several decades) appear to be rare.

The present review firstly examines current evidence of declining and/or stagnating student performance in these primary areas of learning, and then considers the potential effects of three major changes to basic reading conditions in schools in recent years. Finally, as there are still no widely-accepted explanations for this phenomenon, this review also explores the present author's hypothesis: 'Today's classroom reading environment (e.g. increased brightness of lighting and reading material) may well be a latent factor underlying declining literacy and numeracy levels. Although other factors might potentially explain declining student literacy and numeracy (e.g. increased time watching TV and playing digital games, the advent of social media, or perhaps changes in attitudes to learning), long-term comparisons of student test-scores from 1964 to 2003 have rigorously allowed for such influences (Leigh \& Ryan, 2011). The researchers found that despite these factors and other sociological changes, such as immigration, the long-term trend of falling student literacy and numeracy performance over time still remains difficult to account for.

For these reasons, this review incorporates substantially updated findings from a previous review published in the educational research journal Aula Abierta (Loew, Fernández, \& Watson, 2013), however, any prior findings are now re-assessed in the light of additional and novel information subsequently gained through ongoing research by the present author.

The evidence upon which the above hypothesis is based include the following factors to be highlighted in the present review:

1) Visual comfort, visual acuity and reading performance have all been shown to be influenced by the spectral properties of different types of interior lighting;

2) Brightness perception is also largely determined by the spectrum of a given form of lighting;
3) The spectral emissions from fluorescent lamps are vastly dissimilar to all previous forms of illumination;

4) The installation of fluorescent lighting into all Australian primary schools (circa 1980) coincides well with a subsequent rise in unexplained reading and learning disorders in the following decades;

5) 20-year trends of declining student levels of literacy and numeracy appear to be a negative correlate of significant increases in the number and brightness of fluorescent lights in schools during the same period;

6) Break-throughs in bleaching technologies in the 1980s first allowed paper manufacturers to emulate the 'brightening aspirations' of the lighting industry, however, the later addition of Fluorescent Whitening Agents (FWAs) during the 1990s dramatically increased the 'brightness' of paper utilised for reading and writing (hence today's terms 'ultra-white' and/or 'ultra-bright' paper);

7) A growing body of peer-reviewed research now indicates that $5-12 \%$ of students experience at least moderate symptoms of hypersensitivity to brightness and high-contrast repetitive patterns (such as lines of black text on white paper) (Evans \& Allen, 2016; Kriss \& Evans, 2005; Uccula, Enna, \& Mulatti, 2014). This condition (commonly termed MearesIrlen/visual stress syndrome, or Pattern-related visual stress) is best characterised by symptoms of visual discomfort and visual perceptual distortions when viewing text (Evans, Allen, \& Wilkins, 2016), and is hereafter referred to as Visual Stress (VS).

This review will present tangible evidence that VS does indeed play a significant role in reading and learning difficulties, is likely to have a significant effect on overall literacy and numeracy statistics, and that during the past three decades the impact of this very common condition has risen in line with increasingly brighter fluorescent lighting in schools [with most classrooms now having highly-excessive over-illumination 
(Winterbottom \& Wilkins, 2009)]. Moreover, deeper analysis will reveal that the lighting under which today's students learn to read is but one of two dramatic shifts in conditions for reading, the other being that today's printing paper used for reading/writing is also highly-fluorescent! Manufacturers (competing to sell the "whitest/ brightest paper") have been adding fluorescent chemical agents to their products for ca. 20 years.

\section{CURRENT RESEARCH AND CONVERGING EVIDENCE}

\section{STUDENT PERFORMANCE IN LITERACY AND NUMERACY: IS IT REALLY DECLINING?}

To address the above question, international literacy and numeracy tests have been conducted every three years under the Programme for International Student Assessment (PISA). The first of these tests ('PISA 2000') assessed the performance of 15 year-old students in 32 countries, with many more nations taking part in subsequent PISA assessments of student literacy and numeracy achievement in this age group.

Since the inception of PISA, politicians and education authorities in countries such as Australia have tended to base their assessments of national literacy and numeracy achievement levels almost exclusively upon these international comparisons, with the key concern being that their nation's student test-scores have not slipped in the OECD rankings. However, assessing a nation's student literacy and numeracy achievement by using comparisons with other nations is far from ideal, as it might well be the case that many such countries may have experienced declines in these key measures of student performance. For this reason alone, comprehensive studies of medium to long term trends in literacy and numeracy test-scores are particularly warranted. One such study, by Thomson and De Bortoli (2008), compared the test-scores of Australian 15 year-old students in these three successive PISA examinations, and found that overall progress in mathematics in Australian students had stagnated between 2000 and 2006 , with the performance of female students between 2003 and 2006 declining significantly.
In addition, the PISA data also revealed a significant decline in literacy skills for both male and female students between 2000 and 2006.

Later data from PISA 2009 showed that the significant decline in literacy in Australian students from 2000 to 2006 had continued into 2009. The mathematics test-scores of both girls and boys had also declined significantly (from 2003) in PISA 2009 (Thomson, De Bortoli, Nicholas, Hillman, \& Buckley, 2010), moreover, there were significant declines in the number of students attaining higher test-scores (level 5 or 6). In literacy, the percentage of students reaching these higher levels fell from 18\% in PISA 2000 to 13\% in PISA 2009, and those reaching equivalent levels in mathematics fell from 20\% in PISA 2003 to 16\% in PISA 2009.

Subsequent results from PISA 2012 have since become available from the Australian Council for Educational Research (ACER). The later data showed that both literacy and mathematics testscores have continued to decline significantly since 2009, with $36 \%$ of Australian students taking part in PISA 2012 failing to achieve even national baseline proficiency levels in reading literacy while $42 \%$ of students also failed to reach the baseline proficiency level in mathematics literacy (Thomson, De Bortoli, \& Buckley, 2013).

Declining trends in these vital areas of education were also observed in a longerranging study at the Australian National University (Canberra) by Leigh and Ryan (2011). The study tracked the performance of 13-14 year-old Australian students in national literacy tests from 1975 to 1998, and in numeracy tests from 1964 to 2003. The timeframes were selected purely on the basis that only during these periods were the researchers able to trace and isolate an adequate number of identical questions which had been presented to successive groups of Australian school students. The study found a significant decline in numeracy between 1964 and 2003, with Year 9 students in 2003 being a quarter of a grade behind their 1964 counterparts. Moreover, this decline had occurred in spite of an increase in per-child educational funding of $258 \%$ (in real terms) and a $43 \%$ fall in class sizes during the same period. 
There were also significant declines in both literacy and numeracy in the testing results of both male and female students between 1975 and 1998.

The above trends in literacy and numeracy are not peculiar to Australia and have been observed in other developed nations. In the United States, literacy and numeracy test-scores have reportedly remained flat from 1970 to 1998, despite per-child education expenditure rising by $2.5-3 \%$ per year (in real terms) over the same period (Hanushek, 1997). A study by Gundlach, Woessmann and Gmelin (2001) also found that progress in these key areas of education had essentially remained flat in 11 OECD nations from 1970 to 1994, and similarly, there had been dramatic increases in per-child spending in most developed countries over the same period. Increased investment in education by the British government appears to have shown equally poor returns, with a study by Flynn (2009) revealing that the literacy and numeracy test-scores of 14-15 year-old students between 1980 and 2008 had declined.

\section{BRIGHTNESS AND GLARE LEVELS OF OFFICE AND CLASSROOM LIGHTING}

The possible relationship of brightness and glare levels to reading and learning difficulties has been an area of interest for over 20 years (Berman et.al., 1996; Conlon et al., 1999; Irlen, 1994), however, only quite recently have some researchers examined the effects of the typically high levels of illumination found in schools and offices. A study by Winterbottom and Wilkins (2009) measured lighting flicker frequencies, desk illuminance and reflected glare in a sample of 90 classrooms across 17 schools, and found that the lighting in 88\% of UK classrooms greatly exceeds illuminance recommendations, with $84 \%$ having highly excessive illumination ( $\geq 1,000$ lux). The study concluded that any detrimental effects upon learning due to excessive lighting were also likely to be further compounded by reflected glare from whiteboards and other bright visual media. Moreover, studies utilizing fMRI technology have demonstrated that excessive lighting (especially fluorescent lighting) can cause hyperexcitability of the visual cortex, thus provoking migraine headaches and visual stress in susceptible populations (Wilkins et al., 2007).

Why, then, would building designers have a predisposition towards over-illuminating office and classroom settings in the first place? According to Berman et al. (1996), this is in large part due to significant shortcomings in general lighting practice guidelines. The above researchers reviewed a wealth of ophthalmological and vision science research, and then compared this literature to contemporary publications emanating from lighting industry associations, such as the Illuminating Engineering Society of North America (IESNA). They found the key problem to be that virtually all lighting guidelines, and for that matter the calibrations of all illuminancemeasuring devices, are based upon the light sensitivity of only one of the two key types of photoreceptors in the retina. A detailed account of how and why this became standard lighting practice was outlined by Loew et al. (2013, p. 25 ) and is provided in the following paragraphs:

"The fact that our eyes have two types of photoreceptors (the rods and the cones) has been known since early last century, although a third photoreceptor believed to be linked to circadian rhythm has recently been discovered (He, Dong, Deng, Weng, \& Sun, 2003). Conversely, the roles of the rod and cone retinal cells have long been established, with the rods recognized as being night vision (scotopic) receptors and the cones as being day vision (photopic) receptors. However, according to Berman et al. (1996) this traditional view is not only over-simplistic, but is based upon outdated optical measurements, which (from the present authors' view) appear to have been designed 'more for observational convenience, rather than scientific accuracy'.

The basis upon which rod receptors were first assigned the single role of being the night vision receptors' has been hitherto determined through measurements of rod cell responses (scotopic sensitivity) under clearly inadequate conditions (Berman et al., 1996). These early measurements (to which all lighting industry guidelines still adhere) have traditionally been 
carried out under extremely low light levels designed to be well below the threshold of cone sensitivity, thereby excluding any visual input from cone receptors. It appears that because rod receptors can be shown to function efficiently in very faint light, which is well below the lowest sensitivity threshold of cone receptors, this finding was then extrapolated to indicate that the rods are solely night vision receptors. However, the fact that very dim lighting conditions are utilised to isolate rod receptor responses does not automatically rule out the functioning of rod sensitivity at higher light levels, particularly those of typical interior lighting.

In a similar fashion, the methodology employed to measure visual input from cone receptors (photopic sensitivity) has traditionally been carried out under highly unrealistic conditions, which are even more restrictive than those utilised to ascertain rod receptor responses. Indeed, photopic sensitivity is still routinely measured by constricting the test subject's field of view to a maximum of 2 degrees (less than $0.1 \%$ of the normal field of view of the human eye) in order to exploit the absence of rod photoreceptors in the central portion of the retina, thus isolating and measuring only the cone responses (Berman et al., 1990, 1996; Bouma, 1962). As a result of these longstanding methods, current lighting industry recommendations for indoor illumination and room brightness (and the calibration of lightmeasuring devices) have been based solely upon the sensitivity of only one of the two key photoreceptor cell types: the cone receptors (responsible only for photopic sensitivity). The now widely recognised contribution of the rod receptors (scotopic sensitivity) to vision at typical interior lighting levels has been completely excluded from such guidelines, despite the significance of the scotopic contribution under artificial lighting having been reported upon in the prestigious Journal of the Illuminating Engineering Society some two decades ago (Berman et al., 1997). Thus, the lighting industry's guidelines concerning optimal interior illumination have remained unaltered, and evidence of this can be found in modern editions, such as 'The IESNA Lighting Handbook, 9th ed.' (IESNA, 2000)."

\section{PAPER FOR READING AND WRITING: HAS PAPER ALSO CHANGED IN RECENT DECADES?}

The whiteness of writing and printing paper can be important, but only up to a certain point. Whiteness provides good contrast with the ink and can enhance the appearance of a document, particularly with coloured (non-black) text. Typically however, almost all standard text utilises black ink on white paper, and thus there exits an optimal level of whiteness for reading comfort beyond which higher levels of brightness and contrast begin to cause visual fatigue, even visual discomfort. Unfortunately, the whiteness of most paper today now greatly exceeds this highly desirable point, and this is due to the manufacturer, not the consumer (the reader). This situation came about because of a (PC-driven) soaring demand for A4 copy paper during the 1990s, which inevitably led to fierce competition among paper-manufacturers to secure unprecedented high-volume sales of copy paper to businesses, government departments, universities and schools.

Printing paper manufacturers have very little scope for marketing their product, as they cannot enhance the size or thickness of A4 copy paper. It then follows that just a little edge over the competitor in the 'whiteness' and 'brightness' of the paper could create a sellingpoint that leads to increased sales. However, this would inevitably prompt the competitor to develop a paper that is 'slightly whiter' again, which ultimately gave rise to a spiral of increasing whiteness and brilliance to a point well beyond optimal brightness and contrast for the reader. In fact, the whiteness of copy paper long ago surpassed the level for optimal reading comfort, and has now reached levels that can actually cause reading discomfort the very reason that book-publishers do not use such levels of whiteness). The scale of change that has occurred to reading material in recent years can only be truly gauged by comparing the past and present technical specifications of paper, as measured by the most widely used whiteness-index internationally: CIE Whiteness, which has long been recognised as the international measure of white-light reflection properties. 
The CIE Whiteness index (0 - 100) was first defined by the Commission Internationale de I'Eclairage (CIE). For a perfect-reflecting non-fluorescent white material the CIE would be 100, and prior to 1990 the CIE of the whitest papers existing ranged from 75 to 85. However, today's ultra-white papers now often boast CIE measures of 150 to 170 on their packaging. This may seem to be a "CIEWhiteness paradox", however, it has only been made possible by the addition of Optical Brightening Agents (OBAs), also known as Fluorescent Whitening Agents (FWAs), which are fluorescing chemicals designed to absorb light from the non-visible range (ultra-violet) and re-emit it back to the reader's eyes as additional light in the visible spectrum (mostly blue). Apart from this added visible light (circa $20 \%$ ), the human visual system also perceives a higher relative amount of blue light as extra brightness (a fact exploited by laundrydetergent producers, by adding subtle bluedyes to their products). Thus, under typical fluorescent lighting, a brand of paper with a CIE 160 (i.e. 'Reflex Ultra-White') can now not only appear to be $60 \%$ whiter than the maximum level of whiteness possible (CIE 100), it will also reflect back more visible light to the eyes of the reader than that actually received from the light source shining upon it!

Of course, fluorescing OBAs are only functional if and when they are exposed to a light source that also emits ultra-violet light (i.e. fluorescent lighting, and/or sunlight). In fact, under traditional incandescent lighting a paper containing OBAs may often appear to be duller than a paper without added fluorescers, a phenomenon papermanufacturers refer to as 'metamerism'. Accordingly, any potential impact upon reading and learning due to OBAs would not warrant further consideration if it were not for the fact that almost all academic (and office) environments are illuminated (if not overilluminated) by fluorescent lighting emitting substantial amounts of ultra-violet light. As with ultra-white paper, today's fluorescent lamps are also designed to emit higher ratios of blue-light, simply to enhance the observer's perception of 'room-brightness'.

\section{VISUAL STRESS (VISUAL-PROCESSING OVERLOAD)}

High levels of illumination and bright visual media are by no means optimal for enhancing reading, and can actually cause reading discomfort as well as errors (Winterbottom \& Wilkins, 2009). However, those affected are often unaware that such difficulties may be due to the overhead lighting (which varies from room to room), or glare from the printing paper (which varies from brand to brand). The research presented below will substantiate that reading in highly illuminated environments can cause visual distortions, headaches, anxiety (often with hyperactivity), and an earlier onset of visual fatigue and concentration difficulties in around $12-14 \%$ of individuals. These symptoms (most apparent when reading) are believed to be caused by hyperexcitability of the visual cortex, a condition which has become increasingly referred to as Visual Stress. As this condition affects a significant population, and is known to be exacerbated by fluorescent lighting and/or bright white paper, it may well be a latent dynamic in declining literacy and numeracy.

During the past two decades there has been increasing awareness of visual-sensory / perceptual problems which are not caused by optometric or ophthalmological deficits. Such visual processing deficits (believed to affect at least $5 \%$ of the general population) have been termed: Scotopic Sensitivity Syndrome; Visual Processing Disorder; Meares-Irlen/VisualStress Syndrome; and Pattern-Related Visual Stress, however, this common condition is now often more simply referred to as Visual Stress (VS) (Allen \& Hollis, 2008; Kriss \& Evans, 2005). Symptoms of VS include distortions of print (text appears to move or vibrate), deteriorations in reading speed and accuracy within a short period, and sensitivity to fluorescent lighting (Irlen, 1994; Robinson, 1994). The use of coloured filters has frequently been reported to alleviate such symptoms (Allen, Evans, \& Wilkins, 2012; Loew \& Watson, 2012; Wilkins \& Evans, 2009), though others have found no significant benefits (Ritchie, Della Sala, \& Mclntosh, 2011). 
A number of studies in Britain and Australia have reported VS prevalence rates in the population that range from 5\% (Evans \& Allen, 2016) to as high as 22\% (Jeanes et al., 1997; Robinson, Hopkins \& Davies, 1995; Wilkins, Jeanes, Pumfrey, \& Laskier, 1996). Many findings have often been based upon measurable improvements in reading speed, and/or selfreported improvements in symptoms, while subjects are reading through coloured lenses or translucent coloured overlays. Estimations of the prevalence of VS vary widely, and this may in part be due to the intensity of symptoms constituting a continuum (Evans \& Joseph, 2002). Diagnosis of VS can also be difficult due to the severity of symptoms often worsening only after a subject has read continuously for 10 minutes or longer (Evans \& Allen, 2016; Loew, Marsh, \& Watson, 2014; Robinson, 1994).

Identification of VS morbidity can be challenging, as similar or identical symptoms have been identified in a number of independent disorders, including: developmental dyslexia (Northway, Manahilov, \& Simpson, 2010; Rodriguez-Pérez, González-Castro, Álvarez, Álvarez, \& Fernández-Cueli, 2012; Wright \& Conlon, 2009); attention deficit/hyperactivity disorder (Loew \& Watson, 2013; Taurines et al., 2010); chronic fatigue syndrome (Loew et al., 2014; Robinson, McGregor, Roberts, Dunstan, \& Butt, 2001; Wilson, Paterson, \& Hutchinson, 2015) as well as photosensitive epilepsy and migraine (Wilkins, Huang, \& Cao, 2007). Accordingly, research findings indicating that $12-14 \%$ of the general population regularly experience at least moderate symptoms of VS could be viewed as reasonable (Kriss \& Evans, 2005; Kruk, Sumbler, \& Willows, 2008). This is even more so the case if one considers that recent studies have identified similar incidences of VS symptomatology in highly capable readers, including a cohort of PhD students (Loew et al., 2015), and a cohort of Nursing-Degree students (Loew, Marsh, Watson, \& Jones, 2016).

\section{DISCUSSION}

There is now substantial converging evidence indicating that Meares-Irlen/visual stress syndrome is prevalent in a significant proportion of the general population, and that affected individuals are particularly disadvantaged when reading under fluorescent lighting. Whether the incidence of visual stress is $5 \%$ or $15 \%$ is not a key issue, simply because many learning disorders currently being researched worldwide are present in no more than $5 \%$ of the general population. Moreover, much literature also demonstrates that certain forms of interior lighting can affect visual acuity, visual-task performance, concentration and fatigue in most individuals, and not only those who suffer from VS. Furthermore, such research suggests that typical primary school classrooms in developed nations (circa 30 pupils) are likely to contain three or four students who are being significantly disadvantaged by the use of bright visual media, such as ultra-white paper and highly reflective whiteboards, in combination with ever-brighter fluorescent lighting.

In respect to studies reporting excessive lighting in classrooms, as well as anecdotal reports of progressively increasing levels of illumination in schools, offices, and even supermarkets, it has not escaped the current author's attention that the lighting industry may well have a vested interest in adhering to outdated illumination guidelines which have remained in place since 1928. Similarly, the drift away from lighting with a continuous spectrum (mostly emitted in the yellow to red range) appears to be commercially driven, as consumer-demand for more energy-efficient lighting has prompted the lighting industry to develop 'brighter and whiter' fluorescent lamps. However, newer generations of "energyefficient" 36-Watt fluorescent tubes, of course, use exactly the same amount of energy as the "older" 36-Watt tubes that preceded them, with the added brightness (the 'efficiency') being achieved by shifting the spectral distribution towards the blue-violet (scotopic) end of the visible spectrum, thus 'tricking' the brain into perceiving (via the scotopic response of the rod cells) that a room and its contents appear to be brighter. The very same principal has long been used in laundry detergents marketed as "clothing-whiteners", when in actual fact, a small amount of blue-dye has simply been added to the formula. 
Excessive brightness has not only been shown to negatively affect reading efficiency and visual acuity, but also attention, behaviour, headaches and migraine. UK research has revealed that $84 \%$ of classrooms have highly-excessive illumination (e.g. it exceeds 1,000 lux - the point at which notable visual discomfort begins to become a measurable and significant factor for most individuals!) (Winterbottom \& Wilkins, 2009), and other studies suggest that a similar situation exists in most developed nations. Such levels of lighting can only further exacerbate the effects of today's blue-fluorescing ultra-white paper upon reading and learning in schools. In addition, recent years have also witnessed a marked shift in the spectral-balance of fluorescent lighting, with the newer tubes now emitting a far larger proportion light in the blue range (for the sole purpose of making a room appear to be $30 \%$ brighter, thus enabling such lamps to be marketed as "energy efficient").

This review endeavours to explain how and why the reading environment in classrooms has changed dramatically in the past $15-20$ years, with many of those who now approve the use of ultra-white paper in schools (and insist on its use for exams) having themselves learnt to read under entirely different conditions. In this context, the relatively recent introduction of brilliant-white paper into ever-brighter education facilities, from primary schools to universities, has not in any way or form led to increased competency in literacy and numeracy. On the contrary, the present author (who also has VS) believes that changes to the basic reading conditions in schools may well be a key contributor to declining functional-literacy in our high school students, trends which remain unexplained and, despite vast monetary interventions, appear to be irreversible.

In summary, underlying causes are continually being sought to explain the persistently high incidences of students with poor literacy outcomes in several developed nations. It is therefore surprising that educational researchers appear to have not tapped into the plethora of related research available in adjacent fields. If one considers the prevalence of visual stress; the above-cited evidence that similar symptoms can be present in other learning disorders; the research showing that fluorescent lighting is known to exacerbate such symptoms; and the data showing that literacy and numeracy levels have declined over the same period in which the brightness of visual media and fluorescent lighting in classrooms has progressively increased, then surely the focus of some educational research should be directed towards exploring visual and sensory factors.

Finally, this paper was spurred by the hypothesis 'Changes to classroom reading conditions may be affecting literacy and numeracy', which (at this point) appears to fit well with the areas of research examined above, from both a biophysical and a chronological perspective. Therefore, in the absence of alternative explanations for recent trends in student performance, the present author concludes that the above hypothesis may well be viable. Within this context, and as a scientist and education researcher, the author still remains somewhat perplexed by the irony of governments around the world spending vast sums of money in an endeavour to improve literacy and numeracy levels, whilst at the same time, many subsidiary statutory authorities (such as the NSW Board of Studies, in Australia) are altering reading conditions in ways that may actually make reading (and thus learning to read) substantially more difficult. Accordingly, governments may potentially find that closer monitoring of the visual media (e.g. paper) provided to students for learning (and exams) would be a simple and cost-effective means of fulfilling the principal aims of educators; enhancing student literacy, numeracy, and achievement. For these very same reasons, further exploratory research in this area is needed.

\section{Conflict of interest}

The authors declare no conflict of interest.

\section{Acknowledgenment}

The author wishes to thank Estrella Fernández and Kenneth Watson, his co-authors in an earlier manuscript which provided fundamental information to be built upon in the present review. An earlier version of this paper was presented at the VIII International Congress of Psychology and Education (CIPE 2016) in Alicante, Spain. 


\section{REFERENCES}

Allen, P. M., Evans, B. J. W., \& Wilkins, A. J. (2012). The uses of colour in optometric practice to ameliorate symptoms of visual stress. Optometry in Practice, 13, 1-8. doi: hdl.handle.net/10540/263305

Allen, P. M., \& Hollis, J. (2008). Meares-Irlen syndrome - a need for increasing awareness in the general public - Reply. Ophthalmic and Physiological Optics, 28, 291-292. doi: 10.1111/i.1475$1313.2008 .00563 . x$

Berman, S. M., Fein, G., Jewett, D. L., Benson, B. R., Law, T. M., \& Myers, A. W. (1996). Luminance controlled pupil size affects word reading accuracy. Journal of the Illuminating Engineering Society, 25, 51-59.

Berman, S. M., Jewett, D. L, Benson, B. R., \& Law, T. M. (1997). Despite different wall colors, vertical scotopic illuminance predicts pupil size. Journal of the Illuminating Engineering Society, 26, 59-68.

Berman, S. M., Jewett, D. J., Fein, G., Saika, G., \& Ashford, F. (1990). Photopic luminance does not always predict perceived room brightness. Lighting Research Technology, 22, 37-41.

Bouma, H. (1962). Size of the static pupil as a function of wavelength and luminosity of the light incident on the human eye. Nature, 193, 690-691.

Conlon, E. G., Lovegrove, W. J., Chekaluk, E., \& Pattison, P. E. (1999). Measuring visual discomfort. Visual Cognition, 6, 637-663. doi: 10.1080/135062899394885

Evans, B. J. W., \& Allen, P. M. (2016). A systematic review of controlled trials on visual stress using Intuitive Overlays or the Intuitive Colorimeter. Journal of Optometry, 9, 205-218.

Evans, B. J. W., Allen, P. M., \& Wilkins, A. J. (2016). A Delphi study to develop practical diagnostic guidelines for visual stress (pattern-related visual stress). Journal of Optometry. Advance online publication. doi: 10.1016/i.optom.2016.08.002

Evans, B. J. W., \& Joseph, F. (2002). The effect of coloured filters on the rate of reading in an adult student population. Ophthalmic and Physiological Optics, 22, 535-545.

Flynn, J. R. (2009). Requiem for nutrition as the cause of IQ gains: Raven's gains in Britain 1938-2008. Economics and Human Biology, 7, 18-27.

Gundlach, E., Woessmann, L., \& Gmelin, J. (2001). The decline of schooling productivity in OECD countries. Economic Journal, 17 1, C135-C147.

Hanushek, E. A. (1997). The productivity collapse in schools. In W. Fowler Jr. (Ed), Developments in School Finance, 1996 (pp. 183-195). Washington DC, USA: National Center for Education Statistics.

He, S., Dong, W., Deng, Q., Weng, S., \& Sun, W. (2003). Seeing more clearly: recent advances in understanding retinal circuitry. Science, 302, 408411.

IESNA. (2000). The IESNA Lighting Handbook, Reference \&Application. (9th ed.). IESNA, USA: IESNA, New York.
Irlen, H. (1994). Scotopic sensitivity/Irlen syndrome: hypothesis and explanation of the syndrome. Journal of Behavioral Optometry, 5, 62-65.

Jeanes, R., Busby, A., Martin, J., Lewis, E., Stevenson, N., Pointon, D., \& Wilkins, A. J. (1997). Prolonged use of coloured overlays for classroom reading. British Journal of Psychology, 88, 531-548.

Kriss, I., \& Evans, B. J. W. (2005). The relationship between dyslexia and Meares-Irlen syndrome. Journal of Research in Reading, 28, 350-364. doi: 10.1111/i.1467-9817.2005.00274.x

Kruk, R., Sumbler, K., \& Willows, D. (2008). Visual processing characteristics of children with Meares-Irlen syndrome. Ophthalmic and Physiological Optics, 28, 35-46. doi: 10.1111/i.1475-1313.2007.00532.x

Leigh, A., \& Ryan, C. (2011). Long-run trends in school productivity: evidence from Australia. Education Finance and Policy, 6, 105-135.

Loew, S. J., Fernández, E., \& Watson, K. (2013). Incidence of Meares-Irlen/visual stress syndrome in reading and learning disorders: does fluorescent lighting in classrooms affect literacy and numeracy? Aula Abierta, 41, 23-32.

Loew, S. J., Marsh, N. V., \& Watson, K. (2014). The prevalence of symptoms of visual stress/Meares-Irlen syndrome in subjects diagnosed with chronic fatigue syndrome. International Journal of Clinical and Health Psychology, 14, 87-92.

Loew, S. J., Marsh, N. V., Watson, K., \& Jones, G. L. (2016, June). Fluorescent lighting, bright-white paper, and levels of reading discomfort in Nursing-degree students: implications for education and healthcare settings. In Proceedings of the $8^{\text {th }}$ International Congress of Psychology and Education. Alicante, Spain: University of Madrid.

Loew, S. J., Rodriguez, C., Marsh, N. V., Jones, G. L., Núñez, J. C., \& Watson, K. (2015). Levels of visual stress in proficient readers: effects of spectral filtering of fluorescent lighting on reading discomfort. Spanish Journal of Psychology, 18, 1-11.

Loew, S. J., \& Watson, K. (2012). Spectral filtering of fluorescent lighting: effects upon reading and visual discomfort in slow readers. In J. A. Gonzalez-Pienda, C. Rodriguez, D. Alvarez, R. Cerezo, E. Fernandez, M. Cueli, T. Garcia, E. Tuero, \& N.Suarez, (Eds.), Learning Disabilities: Present and Future (pp.267-278). Massachusetts: Learning Disabilities WorldWide ${ }^{\circledR}$.

Loew, S. J., \& Watson, K. (2013). The prevalence of scotopic sensitivity/Meares-Irlen syndrome in subjects diagnosed with ADHD: does misdiagnosis play a role? Croatian Review of Rehabilitation Research, 49, 5058.

Northway, N., Manahilov, V., \& Simpson, W. A. (2010). Coloured filters improve exclusion of perceptual noise in visually symptomatic dyslexics. Journal of Research in Reading, 33, 223-230. doi: hdl.10101/npre.2008.1729.1

Ritchie, S. J., Della Sala, S., \& Mclntosh, R. D. (2011). Irlen colored overlays do not alleviate reading difficulties. Pediatrics, 128, e932-e938. doi: 10.1542/ peds.2011-0314 
Robinson, G. L. (1994). Coloured lenses and reading: a review of research into reading achievement, reading strategies and causal mechanisms. Australian Journal of Special Education, 18, 3-14.

Robinson, G. L., Hopkins, B. R., \& Davies, T. (1995). The incidence of symptoms of Scotopic Sensitivity Syndrome in secondary school populations: a preliminary study. The Bulletin for Learning Disabilities, 5, 36-56.

Robinson, G. L., McGregor, N. R., Roberts, T. K., Dunstan, R. H., \& Butt, H. (2001). A biochemical analysis of people with chronic fatigue who have Irlen syndrome: Speculation concerning immune system dysfunction. Perceptual and Motor Skills, 93, 486504.

Rodriguez-Pérez, C., González-Castro, P., Álvarez, L., Álvarez, D., \& Fernández-Cueli, M. S. (2012). Neuropsychological analysis of the difficulties in dyslexia through sensory fusion. International Journal of Clinical and Health Psychology, 12, 69-80.

Taurines, R., Schmitt, J., Renner, T., Conner, A. C., Warnke, A., \& Romanos, M. (2010). Developmental comorbidity in attention-deficit/hyperactivity disorder. ADHD-Attention Deficit Hyperactivity Disorder, 2, 267-289. doi: 10.1007/s12402-010-0040-0

Thomson, S., \& De Bortoli, L. (2008). Exploring scientific literacy: How Australia measures up. Camberwell, Australia: Australian Council for Educational Research.

Thomson, S., De Bortoli, L., \& Buckley, S. (2013). PISA in brief, highlights from the full Australian report, PISA 2012: How Australia measures up. Camberwell, Australia: Australian Council for Educational Research.
Thomson, S., De Bortoli, L., Nicholas, M., Hillman, K., \& Buckley, S. (2010). Challenges for Australian education: Results from PISA 2009. Camberwell, Australia: Australian Council for Educational Research.

Uccula, A., Enna, M., \& Mulatti, C. (2014). Colors, colored overlays, and reading skills. Frontiers in Psychology, 5, 1-4.doi: 10.3389/fpsyg.2014.00833

Wilkins, A. J., \& Evans, B. J. W. (2009). Visual stress, its treatment with spectral filters, and its relationship to visually induced motion sickness. Applied Ergonomics, 41, 509-515. doi: 10.1016/i. apergo.2009.01.011

Wilkins, A. J., Huang, J., \& Cao, Y. (2007). Prevention of visual stress and migraine with precision spectral filters. Drug Development Research, 68, 469-475. doi: $10.1111 /$ i.1526-4610.2006.00585.x

Wilkins, A. J., Jeanes, R. J., Pumfrey, P. D., Laskier, M. (1996). Rate of Reading Test ${ }^{\circledR}$ : its reliability, and its validity in the assessment of the effects of coloured overlays. Ophthalmic and Physiological Optics, 16, 491-497.

Wilson, R. L., Paterson, K. B., \& Hutchinson, C. V. (2015). Increased vulnerability to patternrelated visual stress in myalgic encephalomyelitis. Perception, 44, 1422-1426.

Winterbottom, M., \& Wilkins, A. J. (2009). Lighting and discomfort in the classroom. Journal of Environmental Psychology, 29, 63-75. doi: 10.1016/i.jenvp.2008.11.007

Wright, C. M., \& Conlon, E. G. (2009). Auditory and visual processing in children with dyslexia. Developmental Neuropsychology, 34, 330-355. doi: $10.1080 / 875656409002801882$

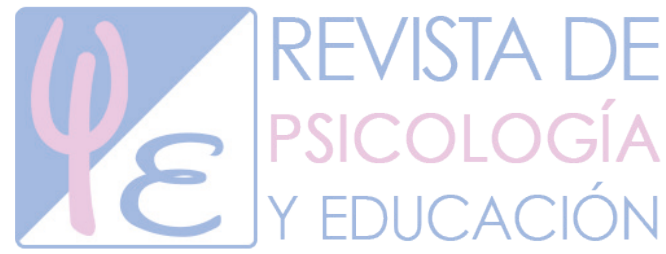

